\title{
RETOS DEL MOVIMIENTO ECOLOGISTA ANTE LA CRISIS GLOBAL
}

\author{
Yayo Herrero \\ Fundación Hogar del Empleado \\ Ecologistas en Acción
}

\section{Resumen.}

El movimiento ecologista cuenta con varias décadas de historia. A pesar de haber conseguido avances importantes en el crecimiento de la conciencia ecológica, la crisis ambiental cada vez es más profunda.

En este momento en el que la crisis ya es civilizatoria, el ecologismo social se centra en el cambio de los imaginarios que no nos permiten tomar conciencia del rumbo al colapso, en la resistencia activista ante las políticas que fomentan la destrucción y en la generación de alternativas que posibiliten una transición justa.

\section{Palabras Clave.}

Límites, imaginarios, ecodependencia, interdependencia, suficiencia

\section{Abstract.}

The history of the environmentalist/ecologist movement goes back various decades. Despite having achieved significant progress in raising environmental awareness, the environmental crisis is extremely severe.

Today, when the crisis affects our dominant model of civilization, social environmentalism focuses on how a change of our collective imaginaries might be encouraged to increase our awareness of the fact that we are heading towards a collapse of our model, that we 
need to put up social and activist resistance to the policies that promote the destruction of our planet, and that we need to generate alternatives that enable a transition based on equity.

\section{Keywords.}

Limits, imaginaries, ecodependence, interdependence and sufficiency

\section{EL ECOLOGISMO ANTE LA CRISIS CIVILIZATORIA}

A comienzos de la década de los setenta el Club de Roma hacía público el informe Meadows sobre los límites al crecimiento. En él se advertía de que, en un planeta con límites físicos, los incrementos permanentes de la extracción de materiales, de la emisión de residuos, de ocupación y degradación del territorio, así como el aumento exponencial de la población humana, no eran viables. El informe alertaba del riesgo que corría la humanidad, si se continuaba con esa tendencia, de llegar a superar los límites del planeta. El informe Meadows supuso un verdadero aterrizaje forzoso en la toma de la conciencia pública de la inviabilidad del crecimiento permanente de la población y sus consumos y puede decirse que es el arranque de un movimiento, el ecologismo social, que superaba las visiones puramente conservacionistas, incidiendo de forma más radical en la incompatibilidad entre la dinámica de los sistemas naturales y un modelo socioeconómico basado en la explotación de territorios y personas, así como en la urgencia en abordar las transiciones hacia otro modelo de organización que permitiese vivir en paz con el planeta.

Hoy, cuarenta años después, la crisis ecológica se ha agravado y se encuentra profundamente interconectada con las crisis económica y social. Nos encontramos ante una verdadera crisis civilizatoria que obliga a repensar las relaciones entre las personas entre sí y con la naturaleza.

Hoy, el movimiento ecologista, en sus diferentes expresiones, tiene importantes retos ante sí. Por una parte, como movimiento político, debe resistir y luchar contra los constantes proyectos e iniciativas que degradan el territorio y las condiciones de vida que vive en ellos; por otro debe contribuir a generar propuestas alternativas al actual un modelo de desarrollo que resulta biocida y, sobre todo, debe trabajar para la transformación de los imaginarios, de los mitos y creencias que impiden que las personas se perciban como seres ecodependientes y actúen para virar el rumbo que conduce al colapso ecológico.

\section{Unas pinceladas sobre el nacimiento de la conciencia ecologista}

Aunque las preocupaciones por la contaminación ambiental, la degradación de los ecosistemas o la conservación de los espacios naturales se encontraba presente desde varios siglos antes, es a partir de la década de los setenta, a raíz de la publicación del informe sobre las límites al crecimiento (Meadows, 1972) cuando podemos situar el 
mayor avance de la conciencia ecologista.

Sus planteamientos empezaron a adquirir una fuerza hasta entonces desconocida y la temática ecológico-ambiental fue ganando terreno en el mundo académico, en el administrativo y en el de los medios de difusión, en consonancia con la mayor sensibilidad de la población (Naredo, 2006).

Con anterioridad a la publicación del informe, ya había habido importantes focos de activismo y denuncia que prepararon el despliegue de la conciencia ecologista. El propio movimiento obrero jugó un importante papel en la lucha contra la contaminación ambiental en aquellos momentos en los que el crecimiento de la actividad industrial enfermaba a las personas que vivían y trabajaban en unas ciudades sumidas en nubes tóxicas emitidas por las fábricas.

La imposibilidad de extraer materiales de forma infinita, la contaminación del agua, el suelo o e aire, los riesgos de arrojar al medio productos xenobióticos a gran escala o las posibles consecuencias del crecimiento ilimitado de la población ya fueron abordados en las obras de personas pioneras como Rachel Carson, Paul Erlich o Boulding a comienzos de los 60. A finales de la misma década, los trabajos de Ivan Illich, André Gorz o Cornelio Castoriadis insistían en la urgencia de llegar a sociedades austeras y autónomas que abandonasen la obsesión por el incremento incesante de la producción y el consumo.

Sin embargo, a pesar de todos estos antecedentes, fue el informe Meadows el que asestó un fuerte varapalo a la viabilidad de un pujante crecimiento económico y situó en el centro del debate la insoslayable conexión física que existe entre la economía y las dinámicas de los sistemas naturales. Esta dimensión material de la economía se vio aún más visibilizada con el estallido en 1973 de la primera crisis energética, a la que seguiría otra en 1979.

La preocupación creciente ante la crisis ambiental condujo a la celebración de Conferencia de las Naciones Unidas de Estocolmo en 1972. Por primera vez se abordaba la crisis ecológica como un problema político global y se establecían una serie de principios que debían reflejarse en la legislación. Un resultado de la conferencia fue la creación del Programa de Naciones Unidas para el Medio Ambiente (PNUMA).

Surgieron múltiples trabajos en todos los ámbitos: académico, político, económico. Entre 1970 y 1980 se publicaban trabajos de una enorme relevancia Environment, Power and Society (Odum, 1971), The Closing Circle (Commoner, 1971), Small is Beautiful (Schumacher, 1973), Energy Basis for Man and Nature (Odum y Odum, 1976) o The Poverty of Power (Commoner, 1976), entre otras, fueron obras que marcaron, y continúan siendo referencia fundamental para el movimiento ecologista.

En todos los lugares del planeta fueron surgiendo núcleos ecologistas que se materializaban en expresiones muy diferentes. Desde las opciones más netamente conservacionistas, que centraban su actividad en la conservación de especies -a veces de una sola especie- y de los espacios naturales, a las organizaciones enmarcadas dentro de la ecología política, 
que incorporaban las crisis social y económica como elementos inseparables de la crisis ecológica; desde las reivindicaciones ecofeministas, que buscaban el diálogo y sinergia entre feminismo y ecologismo, al ecologismo de los pobres relacionado con los conflictos ecológico-distributivos que se derivan de las relaciones Centro-Periferia; desde el ecopacifismo, muy relacionado con la lucha antinuclear y las tensiones producidas por la guerra fría, al el movimiento animalista, que denunciaba el especismo como dominación sobre los animales no humanos...

En estos años nacieron organizaciones como Amigos de la Tierra, Greenpeace, Birdlife o WWF y comenzaron a aparecer opciones verdes dentro de la política institucional. En 1974 fue elegido en Suiza el primer diputado verde en un parlamento estatal y en 1979 se crea el partido verde alemán con Petra Kelly a la cabeza.

Toda esta conciencia creciente sufrió un importante frenazo en la década delos 80 . Aunque es un momento en el que la sensibilidad ecologista crece, se atenúa la preocupación por la contradicción entre el crecimiento económico y los límites físicos del plantea. El abaratamiento de las materias primas, la fe en una tecnociencia que supuestamente iba a permitir avanzar hacia una economía del crecimiento que cada vez requiriese menos materiales y un fuerte aparato de propaganda que calificaba de catastrofistas y apocalípticas las cautelas anteriores, revitalizaban la fe en el crecimiento económico, y nombraban este crecimiento como desarrollo, acompañado de diversos calificativos (sostenible, humano, justo, etc.) (Naredo, 2006).

A partir de ese momento fueron minoritarias las voces que siguieron alertando de los riesgos que comportaba ignorar los deterioros que inevitablemente acompañaban a la producción y al crecimiento desbocado, y se asentó el convencimiento de que era posible alcanzar un crecimiento sostenible de la economía, basado, sobre todo, en las tecnologías verdes.

Salvo valiosas excepciones, la comunidad científica, las administraciones o incluso parte de las organizaciones ambientalistas-ecologistas se fueron olvidando de las preocupaciones que hicieron nacer la conciencia ecologista obviando las raíces económicas del deterioro ambiental. Se empeñaron en tratar de alcanzar un "desarrollo respetuoso con el medio ambiente y compatible con el crecimiento de la economía" que, articulado a través de los instrumentos de mercado de la economía convencional, confiaba en las aportaciones que la tecnología podía realizar en términos de ecoeficiencia. Indudablemente, en los países del Centro se consiguieron grandes avances en legislación medioambiental que, en muchos casos mejoraron la calidad del aire o a protección de las personas antes los riesgos químicos, pero estos avances se realizaron a costa de externalizar los efectos nocivos a otros territorios de la Periferia, tal y como reflejan los trabajos de la economía ecológica (Martínez Alier 2004; Carpintero,2005; Naredo, 2006).

Muchas organizaciones ecologistas asumieron la idea de era posible compatibilizar el crecimiento económico con la conservación de los ecosistemas y las luchas por la 
preservación de la naturaleza y de las especies se desvinculó, en buena medida de la denuncia y exigencia del cambio hacia un modelo social y económico que fuese justo y sostenible. Aquella parte del movimiento ecologista, el ecologismo social, que continuó centrada en señalar la incompatibilidad del crecimiento económico basado en la extracción creciente de materiales y la generación de residuos con la conservación de la naturaleza y la justicia, fue incorporada dentro del saco de los movimientos tildados como radicales y antisistema.

Durante las últimas décadas hemos visto avances en la inclusión de temas ecologistas en las agendas políticas: las energías renovables, la gestión del agua, la preocupación por la polución, la aparición de figuras de protección de los espacios naturales, la creación de leyes e instrumentos jurídicos para la defensa del medio ambiente, etc. Sin embargo, los grandes problemas ambientales han ido a peor. Los desórdenes de los mecanismos de autorregulación del clima, el agotamiento de recursos naturales, el crecimiento de los residuos, la desertificación, la pérdida de biodiversidad y la alteración de los servicios ecosistémicos, etc.

Es evidente que el aumento de especialistas, publicaciones, departamentos, fundaciones, instrumentos económicos de la economía ambiental, o el marketing verde no han conseguido desviar el camino hacia el colapso. Todos los indicadores que dan cuenta del deterioro global muestran cómo la situación empeora. La extracción de recursos y la emisión de residuos per capita siguen aumentando a escala planetaria abocando a la humanidad a un horizonte de destrucción cada vez más cercano.

En efecto, más de 30 años después, una revisión del informe Meadows (2004) mostraba que, lejos de frenarse la tendencia, se ha acelerado. La humanidad ya no se encuentra en riesgo de superar los límites de la biosfera, sino que ha llegado a una situación de translimitación (García, 2006)

La Evaluación de los Ecosistemas del Milenio (Reid et al., 2005), un trabajo impulsado por la ONU, apoyaba estas afirmaciones. Después de analizar el estado de los ecosistemas planetarios concluye que las dos terceras partes de los servicios que prestan los ecosistemas están ya alterados. De seguir por el mismo camino, dentro de apenas unas décadas podría ser completamente imposible atender y resolver los problemas de pobreza en el mundo. El Informe Sobre la Situación del Mundo 2013, elaborado por el Worldwatch Institute (2013) se pregunta si aún es posible lograr la sostenibilidad después de analizar cómo a pesar de as innumerables cumbres, la ingente cantidad de congresos, seminarios y eventos, las emisiones de gases de efecto invernadero aumentan, crecen las emisiones de tóxicos y químicos, se han incrementado los fenómenos climáticos extremos fruto del calentamiento global, los océanos se han acidificado, aumentas las guerras por los recursos naturales, disminuyen las reservas pesqueras, aumentan los precios de los cereales y materias primas,...

Es obvio que la ecoeficiencia no ha permitido disminuir la presión sobre el medio 
físico, ya que los ahorros obtenidos han sido anulados por el aumento de la escala de la fabricación y consumo. La desmaterialización de la economía, hoy por hoy, es una falacia (Carpintero, 2005) y el incremento del Producto Interior Bruto continúa acoplado con el aumento del uso de materiales y energía y la generación de residuos. Se demuestra así que la sostenibilidad no es sólo un asunto tecnológico, aunque la tecnología pueda ser necesaria para salir de la situación. Nos encontramos ante un grave problema sistémico que requiere cambios políticos, sociales, económicos y éticos.

\section{Mayores dificultades en el momento actual}

En la actualidad una buena parte del mundo rico afronta una crisis económica y social y sufre unos ajustes estructurales similares a los que los países de la Periferia han venido soportando desde hace décadas.

La precariedad y la vulnerabilidad social hacen mucho más difícil que las personas sean conscientes, se preocupen o se muevan ante el más que previsible colapso ambiental.

Con una tasa de desempleo desbocada es más difícil ayudar a comprender que inevitablemente tendremos aprender a vivir con menos materiales y energía si queremos transitar sociedades justas y compatibles con el funcionamiento de lo vivo. Durante muchos años fuimos tildados de cavernícolas y alejados de la sociedad al plantear que hacían falta menos carreteras y coches, que era necesario disminuir el consumo de energía y la generación de residuos, que los viajes en avión debían espaciarse lo más posible, que debíamos apostar por una dieta más vegetariana, o comer alimentos producidos cerca y de temporada. Si en época de vacas gordas estos planteamientos parecían estar fuera de toda lógica, con la crisis económica la preocupación por los temas del ecologismo pasa a ocupar los últimos lugares de la agenda política.

Y sin embargo, para salir de esta crisis global resulta más urgente que nunca comprender que el medio ambiente no es una parte de la economía sino que, muy al contrario, es sistema económico se encuentra inserto dentro de la Biosfera; visibilizar que el aumento del PIB sigue directamente acoplado al uso creciente de materiales y energía que ya se encuentran en declive; que las soluciones tecnológicas a menudo no sirven para resolver los problemas que ellas mismas han causado; que el dinero no sustituye al capital natural; que los procesos económicos no están al margen de las leyes de la termodinámica; que no existe una salida real y justa a la crisis global que no pase por la sostenibilidad.

El reto del movimiento ecologista es múltiple. En primer lugar debe ayudar a visibilizar que muchos de las mitos que sostienen nuestra cultura se basan en ficciones que denominan desarrollo y progreso al deterioro social y ambiental y alimentan una creencia peligrosa: la de que cada ser humano es autónomo, tanto de la naturaleza como del resto de las personas Descubrir el andamiaje cultural que sostiene estas visiones es importante para poder diseñar las transiciones hacia otras formas de vida. Impulsar una revisión de los esquemas mentales con los que comprendemos y actuamos en el mundo es tarea 
fundamental para el movimiento ecologista (Herrero, 2013).

En segundo lugar, debe resistir y luchar contra proyectos, leyes o acuerdos que se desarrollan en contra de los ecosistemas y de las personas. En concreto, en el estado español existen decenas de frentes abiertos: desde la especulación urbanística y su tsunami de cemento (Fernández Durán, 2008) que ha dado lugar a la actual crisis económica, la lucha antinuclear, la resistencia contra los transgénicos, la oposición a los proyectos de fracking, la resistencia a la destrucción del litoral y del mar, la expansión de regadíos ilegales, la lucha contra las grandes infraestructuras y los macroproyectos - tan ligadas a la corrupción - la defensa de las especies en peligro, la moratoria a las energías renovables, la lucha contra la pobreza energética y contra el riesgo químico...

En tercer lugar, el movimiento ecologista tiene que participar activamente en la generación de alternativas y contribuir, con otros movimientos político-sociales, a construir mayorías sociales que deseen estos cambios. Esta construcción de mayorías enlaza con el primero de los retos, el del cambio de los imaginarios.

Y en cuarto lugar, el cambio es urgente. Algunos de los elementos de la crisis ecológica serán irreversibles si no se consiguen cambios significativos en los próximos años.

Teniendo en cuenta el profundo y acelerado cambio climático, el agotamiento de la energía fósil barata y de muchos minerales que sostienen el metabolismo económico y los estilos de vida, tal y como los conocemos; siendo conscientes de la huella ecológica global creciente y desigual; sabiendo del declive del agua dulce y la alteración de los ciclos naturales, especialmente el del carbono y el nitrógeno; experimentando la profundización en las desigualdades sociales, la desresponsabilización del estado y la sociedad del cuidado de las personas; asistiendo al intento de incremento del control sobre el cuerpo de las mujeres, al aumento de la represión y el auge de los fascismos... parece ingenuo pensar en que se pueda salir de este atolladero a partir de meras reformas puntuales, por más que incluso las medidas más tibias y reformistas puedan parecer radicales ante esta ofensiva neoliberal (Herrero, 2013).

Repensar la economía desde una perspectiva ecologista implica volver a las preguntas básicas: ¿Qué papel ocupa nuestra especie en la Biosfera? ¿Cómo se sostiene la vida humana? ¿Cuáles son nuestras necesidades? ¿Cómo podemos producirlo para todos y todas? ¿Cómo nos organizamos para hacerlo?

En las páginas que siguen vamos a tratar de esbozar la naturaleza de algunos de estos retos que ya han sido esbozados en otros trabajos (Herrero et al., 2011; Herrero, 2012).

\section{SOMOS ECODEPENDIENTES E INTERDEPENDIENTES}

Los seres humanos somos una especie de las muchas que habitan este planeta y, como todas ellas, obtenemos lo que necesitamos para estar vivos de la naturaleza: alimento, agua, cobijo, energía, minerales... Por ello, decimos que somos seres radicalmente ecodependientes. En realidad somos naturaleza. 
Sin embargo, las sociedades occidentales son prácticamente las únicas que establecen una ruptura radical entre naturaleza y cultura; son las únicas que elevan una pared entre las personas y el resto del mundo vivo (Riechmann, 2009). Concebir lo humano como opuesto y superior a la naturaleza impide comprender las relaciones de dependencia y aboca a destruir o alterar de forma significativa la dinámica que regula y regenera lo vivo, en una tendencia absolutamente suicida. La denuncia de esta visión antropocéntrica es uno de los elementos constituyentes del movimiento ecologista.

El imaginario colectivo está profundamente penetrado por la lógica de la dominación sobre la naturaleza. Sumida en un preocupante analfabetismo ecológico, una buena parte de la sociedad y muchas de sus instituciones continúan ignorando la complejidad y autoorganización de los sistemas vivos.

La mayor parte de la ciudadanía no se siente ecodependiente y considera que la ciencia y la técnica serán capaces de resolver todos los deterioros que ellas mismas crean. De forma mayoritaria se profesa un optimismo tecnológico que hace creer, acríticamente, que algo se inventará para sustituir los materiales y recursos energéticos que son velozmente degradados en el metabolismo económico, o para reestablecer la biocapacidad del planeta, actualmente ya superada.

Pero además, somos seres profundamente interdependientes. Desde el nacimiento hasta la muerte, las personas dependemos física y emocionalmente del tiempo que otras personas nos dan. Somos seres encarnados en cuerpos que enferman y envejecen. Durante toda la vida, pero sobre todo en algunos momentos del ciclo vital, las personas no podríamos sobrevivir si no fuese porque otras - mayoritariamente mujeres debido a la división sexual del trabajo que impone el patriarcado- dedican tiempo y energía a cuidar de nuestros cuerpos. La invisibilidad de la interdependencia, la desvalorización de la centralidad antropológica de los vínculos y las relaciones entre las personas y la subordinación de las emociones a la razón son rasgos esenciales de las sociedades patriarcales (Hernando 2012).

Y si no miramos la vejez, la enfermedad o la muerte, no podemos ver la centralidad del trabajo de quienes se ocupan del mantenimiento y cuidado de los cuerpos vulnerables. Y si no lo vemos, seguiremos apostando por sociedades en las que cada vez es más difícil reproducir y mantener la vida humana, porque el bienestar de las personas con sus cuerpos no es la prioridad (Carrasco, 2009).

\section{SOMOS EN UN MUNDO CON LÍMITES... YA SUPERADOS}

La dependencia ecológica nos sume de lleno en el problema de los límites. Vivimos en un mundo que tiene límites ecológicos. Aquello que es no renovable, como los minerales o la energía fósil tiene su límite en la cantidad disponible, y aquello que se renueva, como el agua, por ejemplo, también tiene límites ligados a la velocidad de regeneración. Existen nueve límites planetarios en los procesos biofísicos que son fundamentales 
para garantizar la continuidad de los procesos de la naturaleza. Estos nueve límites, interdependientes entre ellos, dibujan un marco dentro del cual la humanidad puede desenvolverse con cierta seguridad (Rockström et al., 2009). Sobrepasarlos nos sitúa en un entorno de incertidumbre a partir del cual se pueden producir cambios a gran escala y velocidad que conduzcan a la emergencia de otras condiciones naturales menos favorables para la especie humana.

Estos límites hacen referencia al cambio climático, el ritmo de extinción de la biodiversidad, a los ciclos del nitrógeno y el fósforo, el agotamiento del ozono estratosférico, la acidificación de los océanos, la utilización de agua dulce, los cambios de uso de suelo, la contaminación atmosférica por aerosoles y la contaminación química (plásticos, metales pesados, alteradores hormonales, residuos radiactivos, etc,).

De estos nueve límites, los cuatro primeros ya están sobrepasados (Rockström et al., 2009). El metabolismo económico actual no se apoya sobre la riqueza que la naturaleza es capaz de regenerar, sino que menoscaba los bienes de fondo que permiten esa regeneración. Conviene no olvidar que nuestra especie está adaptada a esta composición de la atmósfera, a esta temperatura media y que no hemos brotado como una seta en el planeta tierra, sino que como especie hemos co-evolucionado con una gran cantidad de especies vegetales, animales o microorganismos. Una biodiversidad que constituye un verdadero "seguro de vida para la vida” (Riechmann, 2005).

\section{El pico del petróleo}

Desde un punto de vista mucho más mecanicista, nos encontramos con los límites ya inevitables que imponen el declive de la energía fósil barata y el de muchos minerales imprescindibles para sostener las sociedades basadas en una enorme movilidad de personas y materiales.

La propia Agencia Internacional de la Energía ha manifestado que el pico del petróleo - ese momento en el que por cada barril de petróleo que se extrae no se encuentran reservas para sustituirlo- se alcanzó en 2006. Una vez alcanzado este pico, la obtención de petróleo comenzaría a declinar.

Las energías renovables y limpias pueden satisfacer las necesidades humanas pero no a la escala de las exigencias de un modelo de producción, distribución consumo, sumamente energívoro, que además pretende continuar creciendo (Fernández Durán, 2008).

La economía capitalista ha crecido a expensas de la energía barata y aparentemente inagotable que proporcionaba el petróleo (Naredo, 2006: 47). Éste ha servido para mover máquinas e impulsar vehículos de automoción, para producir electricidad. El petróleo es imprescindible en la agricultura intensiva y en la producción de insumos agrícolas, lo es también en la fabricación de ropas, casas, muebles, carreteras, envases... Las grandes urbes son inviables sin energía abundante y barata. Vivimos en un mundo construido con petróleo y su agotamiento, queramos o no modificará todo el modelo de vida. 
La idea de progreso se relaciona, en muchas ocasiones, con la superación de aquello que se percibe como un límite. La dominación sobre la propia vida de la que formamos parte toma cuerpo en la obsesión por eliminar los obstáculos que impidan la realización de cualquier deseo. La modificación de lo que viene dado por la naturaleza ha sido vivida como un muestra de progreso (Alba Rico y Fernández Liria, 2012). En la cara oculta de la superación de los límites se sitúa la destrucción, agotamiento o deterioro de aquello que necesitamos para vivir.

\section{UNA MITOLOGÍA QUE ESCONDE EL COLAPSO ECOLÓGICO}

A la vez que el movimiento ecologista intenta influir en el plano político y socioeconómico para transitar a un mundo justo y sostenible, también resulta fundamental analizar y comprender sobre qué piso se sostiene nuestra cultura, cuáles son los dogmas y mitos a través de los que interpretamos y actuamos en todo lo que nos rodea para intentar influir en los imaginarios que los sostienen. Por ello, un empeño fundamental en el trabajo ecologista es la deconstrucción de lo imaginarios con los que comprendemos el mundo y actuamos en él.

Conviene desvelar algunas de sus ficciones para recomponer un conocimiento que permita reorientar la economía y la sociedad y nos permita comprender la subjetividad que se ha construido fruto de esa cultura. En este trabajo de revisión, las perspectivas que ofrecen algunas visiones heterodoxas de la economía crítica, como son la economía ecológica y la economía feminista, realizan una aportación muy relevante. Tal y como hemos sostenido en otros trabajos, se enumeran a continuación algunas de las creencias que sostienen esta visión distorsionada (Herrero, 20013).

\section{Primer mito del fundamentalismo económico: la producción puede desvincularse de la} vida.

La economía capitalista reduce el concepto de valor al de precio, desplazándose el peso desde el valor de uso y la satisfacción de necesidades al valor de cambio y la generación de beneficios.

Esta reducción hace desaparecer del campo de análisis económico todo aquello que no se cambia por dinero. La mayor parte de lo que sostiene materialmente la vida humana desaparece de la economía, aunque siga siendo imprescindible para mantener la vida. La reducción del campo del valor a lo exclusivamente monetario expulsa del campo de estudio económico la complejidad dela regeneración natural y todos los trabajos humanos que no formaban parte de la esfera mercantil, que pasan a ser invisibles (Naredo, 2006; Carrasco, 2009).

La producción pasa a ser cualquier proceso en el que se produce un aumento de valor, medido en términos monetarios. Cuando la producción se mide exclusivamente en euros, la economía y la sociedad dejan de preguntarse por la naturaleza de lo que se produce, 
por las necesidades que satisface y se pierde la capacidad de discriminar entre aquellas producciones necesarias para sostener la vida humana y aquellas otras "producciones" que destruyen la posibilidad de mantenerla.

Para construir una economía adecuada a los seres humanos, la producción tiene que ser una categoría ligada al mantenimiento de la vida y al bienestar de las personas (Pérez Orozco, 2006a; 2006b) y además debe ser compatible con la vocación de los territorios y los ritmo de la naturaleza (Naredo, 2006). Hay producciones que son socialmente necesarias y otras socialmente indeseables, por más duro que resulte decirlo en un momento en el que el desempleo está disparado. Distinguir entre ambas es imprescindible y los indicadores monetarios al uso no lo permiten.

\section{Segundo mito del fundamentalismo económico: tierra y trabajo sustituibles por capital}

La teoría económica neoclásica postula que tierra y trabajo son siempre sustituibles por capital. Pero para producir cualquier cosa hace falta trabajo humano, tierra, minerales, energía y la capacidad de regeneración de los ciclos naturales. Si estos recursos no existen en el lugar en el que se pretende producir, habrá que traerlos de otros lugares.

¿Son sustituibles, entonces, la tierra y trabajo por el dinero? Mientras haya otras tierras a las que comprar a bajo precio la energía, los materiales y la mano de obra puede que sí pero, según la humanidad se va ampliando la intervención humana en el planeta, cada vez quedan menos lugares para seguir expoliando. Los insalvables límites físicos muestran cómo, una vez esquilmados los stocks de materiales y alterados irreversiblemente los procesos naturales, por más que se pague no se puede regenerar lo destruido.

Una vez superados los límites del planeta, la reducción del tamaño de la esfera material de la economía global no es discutible. La llamada pobreza energética que comienza a aflorar también en los países enriquecidos evidencia la injusticia de mantener un esquema desigual en el acceso a la energía. Ante el declive y encarecimiento de la energía fósil - en buena medida sujeta a procesos especulativos - el ecologismo social, que apuesta por la existencia de sociedades justas e igualitarias, defiende que el esfuerzo de austeridad material deberá ser realizado mayoritariamente por los territorios, y dentro de ellos las personas, que sobreconsumen por encima de lo que permiten sus propios territorios.

\section{Tercer mito del fundamentalismo económico: producir más es siempre mejor}

Cuando se reduce el valor de un bien o un proceso al valor monetario que se le otorga, la única dimensión que crea valor en el mercado es su precio.

El precio de un determinado producto no incorpora la inevitable generación de residuos que acompaña a cualquier proceso de transformación, ni tampoco el agotamiento de recursos finitos, ni la explotación de trabajadores y trabajadoras... La economía convencional no tiene apenas herramientas para poder medir ese deterioro y celebra cualquier tipo de producción que genera beneficio económico, aunque por el camino se 
destruya el presente y el futuro de sociedades y ecosistemas.

Así, ignorando las externalidades negativas, es como se ha llegado a construir el dogma intocable de la economía convencional: el que defiende que cualquier crecimiento económico, independientemente de la naturaleza de la actividad que lo sostiene, es positivo en sí mismo, constituyendo la única forma de garantizar el bienestar social.

La necesidad de que la economía crezca sirve de justificación lo mismo para arrebatar derechos laborales, que para destruir el territorio, para eliminar servicios públicos o para reformar el código penal... Y las personas lo tenemos tan incorporado en nuestros esquemas racionales que apenas se escuchan voces críticas que denuncien la falacia y el riesgo de perseguir el crecimiento económico como un fin en sí mismo, sin preguntarse a costa de qué, para satisfacer qué y quién se apropia los beneficios de ese crecimiento.

\section{Cuarto mito del fundamentalismo económico: trabajo es sólo lo que se hace a cambio del salario.}

Con el nacimiento de la industria y el proceso de desposesión del campesinado nació el proletariado, una gran masa de personas sin medios de producción que para subsistir se vieron obligados a vender su fuerza de trabajo a los dueños de esos medios de producción. El trabajo pasó a ser concebido como aquello que se hacía en la esfera mercantil a cambio de un salario, y todas aquellas funciones que se realizaban en el espacio de producción doméstica que garantizaban la reproducción y cuidado de los cuerpos humanos pasaron a no ser nombradas, aunque obviamente seguían siendo imprescindibles tanto para la supervivencia como para fabricar esa "nueva mercancía" que era la mano de obra (Carrasco, 2009).

De un plumazo se ocultaba una parte de la existencia que no tenía reflejo en el mundo monetario y que se subordinaba a las lógicas y exigencias de una economía hipertrofiada. La nueva economía transformó el trabajo y la tierra en mercancías y comenzaron a ser tratados como si hubiesen sido producidos para ser vendidos.

La nueva noción del trabajo exigió hacer el cuerpo apropiado para la regularidad y automatismo exigido por la disciplina del trabajo capitalista (Federeci 2010), el cuerpo se convierte en una maquinaria de trabajo. $\mathrm{Y}$ su regeneración y reproducción no es responsabilidad de la economía que se desentiende de ellas, relegándolas al espacio doméstico. Allí, las mujeres se ven obligadas a asumir esas funciones desvalorizadas socialmente a pesar de que sean tan imprescindibles tanto para la supervivencia digna como para el propio mantenimiento de la producción capitalista (Carrasco, 2009).

Paradójicamente, es el espacio mercantil, en el que la solidaridad y el cuidado de la vida están suspendidos, el que organiza el tiempo y el territorio. Tiempo y territorio no son más que naturaleza y vida humana que, bajo esta lógica pasan a estar organizadas en torno a los beneficios. Y, además, es este espacio mercantil, en el que la moral está 
suspendida, el que puede otorga derechos económicos y sociales. Es la participación en este espacio el que permite autonomía económica y protección social.

\section{HACIA UNA NUEVA RACIONALIDAD ECOLÓGICA Y ANTIPATRIARCAL: APRENDER A VIVIR CON MENOS}

El movimiento ecologista se rebela contra la idea repetida hasta la náusea de que fuera de la lógica capitalista no hay alternativa.

No pretendemos caer en la ingenuidad de sostener que la transición hacia otro modelo compatible con los límites del planeta se vaya a poder realizar sin conflicto o que existan hojas de ruta claras sobre lo que habría que hacer.

El ecologismo es consciente de que las propuestas existentes probablemente son incompletas e inmaduras, seguramente no serán perfectamente coherentes unas con otras, y presentarán dificultades no imaginadas para poder ser materializadas pero, sin duda, constituyen un punto de partida para la reflexión.

Ramón Fernández Durán solía plantear que, para él, una sociedad que mereciese la pena tendría que ser socialista, ecológica, antipatriarcal y alegre. Nosotras coincidimos con él y creemos que el camino hacia esta utopía impone una serie de condicionantes irrenunciables que obligan a trastocar los mitos y ficciones a los que nos hemos referido anteriormente sobre los que se construye el relato cultural de nuestras sociedades.

El primero de estos condicionantes tiene que ver con el inevitable decrecimiento de la esfera material de la economía. No es tanto un principio que se pueda o no compartir; es más bien un dato de partida. Se decrecerá materialmente por las buenas - es decir de forma planificada y justa - o por las malas - por la vía de que cada vez menos personas, las que tienen poder económico y/o militar sigan sosteniendo su estilo de vida a costa de que cada vez más gente no pueda acceder a los mínimos materiales de existencia digna. Si asumimos el inevitable ajuste a los límites del planeta, es obvia la obligación de asumir que las sociedades ecológicas forzosamente tendrán que ser más austeras en el uso de materiales y generación de residuos, se deberán basar en las energías renovables y limpias, se articularán en la cercanía, cerrarán los ciclos, conservar la diversidad y tendrán que ser mucho, mucho más lentas (Riechmann, 2005).

El segundo condicionante tiene que ver con la interdependencia. Habitualmente el concepto de dependencia se suele asociar a la crianza, a la atención de personas enfermas o con alguna diversidad funcional. Sin embargo, la dependencia no es algo específico de determinados grupos de población, sino que como expone Carrasco "es la representación de nuestra vulnerabilidad; es algo inherente a la condición humana, como el nacimiento y la muerte" (Carrasco, 2009: 178). Por tanto, es una característica universal: todos y todas somos dependientes y necesitamos cuidados.

Aceptar la interdependencia, condición para la existencia de humanidad, en sociedades 
no patriarcales supone que la sociedad en su conjunto se tiene que hacer responsable del bienestar y de la reproducción social.

Ello obliga a cambiar la noción de trabajo, que deberá ser una actividad humana básica e imprescindible, que cree riqueza real capaz de satisfacer necesidades humanas de forma equitativa y sostenible; el trabajo supondrá relacionarse con la naturaleza y con el resto de las personas y conseguir medios para poder vivir dignamente y, por ello, no estará falsamente escindido del resto de la vida (Bosch et al., 2005).

Una tercera condición es el reparto de la riqueza. En un planeta físicamente limitado, en el que un crecimiento económico ilimitado no es posible, la justicia se relaciona directamente con la distribución y reparto de la riqueza.

Rentas mínimas, rentas máximas, una fiscalidad progresiva, poner límites a la propiedad ligada a la acumulación... La política económica ha desarrollado múltiples instrumentos para repartir la riqueza (tierra, trabajo y capital) que están absolutamente vigentes en el momento actual. Será obligado la legitimidad de la propiedad ligada a la acumulación.

Cómo desarrollar una buena vida con menos materiales y energía, de forma que este bienestar sea universalizable a todas las personas, es núcleo central de la preocupación ecologista. Romper los vínculos simbólicos que hoy identifican la sociedad de consumo con la calidad de vida es una premisa inaplazable.

El movimiento ecologista, junto con otros movimientos sociales y corrientes de pensamiento, se encuentra involucrado en la generación de propuesta que pueda ayudar en las transiciones.

\section{Cambiar el modelo de producción}

Para convertir a la producción en una categoría ligada al mantenimiento de la vida, es preciso repensar qué se produce, cómo y cuánto se produce.

Los ejes del nuevo modelo productivo deberán basarse en la utilización de fuentes de energía renovable, en el cierre de los ciclos de materiales, en el mantenimiento de la biodiversidad, en creación de canales cortos de comercialización y relocalización de la producción y en la aplicación del principio de precaución.

La reconversión obligaría, tal y como señalan Carpintero y Bellver (2013) a actuar en el terreno de la ordenación del territorio, en la reconversión del sector de la construcción, en la formulación de políticas integradas de gestión de recursos como el agua y la energía, en el establecimiento de políticas coherentes de gestión de residuos, en la reconversión de la agricultura y modelo alimentario, en una reconversión industrial que aplique los principios de la industria limpia, en el fomento de empleos en el ámbito de la economía social, solidaria y sostenible, en la transformación del sistema financiero y en el establecimiento de una política fiscal alternativa orientada con criterios ecológicos y sociales.

No sólo basta saber qué y cómo producir. Es preciso también fijarse en cuánto es posible 
producir. En este sentido, es importante introducir politicas de gestión de la demanda, encaminadas a reducir el consumo en focos y sectores sociales que sobreconsumen, de forma que se logre una reducción neta de la cantidad de materiales y residuos que, hoy, pone en juego el metabolismo económico. La reorganización de la sociedad asumiendo estas políticas, obliga a abrir una debate social sobre las necesidades, sobre las producciones necesarias para satisfacerlas y sobre los trabajos socialmente necesarios para lograr esas producciones.

Además, es preciso reformar los sistemas de contabilidad nacional, de modo que se incorporen estadísticas y análisis basadas en indicadores que den cuenta del territorio y del tiempo de las personas. La economía ecológica ha trabajado en la propuesta de indicadores que tienen que ver con la dimensión biogeofísica y desde la economía feminista se ha incidido de una forma acentuada sobre la organización del tiempo.

El movimiento ecologista ha trabajado mucho en la elaboración de propuestas que pueden servir de base para las transiciones socioecológicas. No es objeto de este trabajo realizar una compilación de proyectos, estudios y experiencias que evidencian que es posible afrontar de forma alternativa muchas de las dimensiones de la crisis actual ${ }^{1}$. Pero la mayor parte de los ámbitos de actuación señalados anteriormente existen líneas de trabajo abiertas que podrían servir para reorganizar la economía y la sociedad de otro modo.

En concreto, en el estado español se han desarrollado modelos alternativos para afrontar las transiciones socioecológicas ${ }^{2}$ en ámbitos diversos como el energético, el del transporte, la agricultura, la edificación, el urbanismo, la pesquería,...

Existen propuestas sobre cómo reconfigurar el sistema fiscal y repartir la riqueza o sobre cómo reorientar los subsidios que destruyen la biodiversidad ${ }^{3}$. Hay pensamiento elaborado sobre la banca y las finanzas o el desarrollo de los sectores y trabajos socialmente necesarios.

1. La editorial Akal ha publicado entre 2012 y 2013 una colección de libros que abordan las transiciones hacia otro modelo de sociedad diferente en diferentes ámbitos: ecología, energía, agua, etc. Una buena parte de esos trabajos han sido realizados por personas pertenecientes al movimiento ecologista. Pueden ser consultados en la página web http://www.quehacemos.org/

2. Existe una interesante serie de informes que apuntan a las transiciones socioecológicas en diferentes ámbitos elaborados dentro del programa Cambio Global España 20202050 del Centro Complutense de Estudios e Información Medioambiental, que pueden se consultados en (www.ucm.es/info/fgu/.../ cceim/index_cceim.php). En concreto, se abordan propuestas de transición en el ámbito de la edificación, la energía, el consumo, el transporte o la ordenación del territorio. En la elaboración de todos estos informes han intervenido personas pertenecientes al movimiento ecologista.

3. Puede consultarse la crítica y propuesta que realiza la organización Ecologistas en Acción en https:// www.ecologistasenaccion.org/article26526.html 


\section{Participar y alentar la creación en las experiencias alternativas}

Durante los últimos años han proliferado múltiples experiencias que intentan ensayar modos alternativos de producir, cuidar o distribuir, de gestionar la propiedad, de financiar proyectos y a colectivos...

Las personas organizadas en cooperativas de consumo agroecológico en todo el estado se cuentan por miles; existen cooperativas de servicios financieros como Coop 57 o Fiare, que ya cuentan con más de 15 años de vida y con unas cantidades de dinero prestado nada despreciables; existen redes de cuidados compartidos que resuelven necesidades de atención a niños y niñas; residencias de mayores autogestionadas basadas en el apoyo mutuo; proyectos de cooperativas integrales y mercado social: medios de comunicación alternativos; cooperativas de servicios energéticos basados en las renovables como Som Energia o Ecoo.

Estas experiencias son laboratorios sociales, a la vez que satisfacen las necesidades concretas de quienes participan en ellas. Alentar estos proyectos, aunque sean pequeños y no supongan una alternativa global, es muy importante porque además preparan a las personas y colectivos para disputar el poder en todos los ámbitos. La participación del ecologismo social en todas estas iniciativas es intensa y constituye también una importante línea de trabajo.

\section{CÓMO CONSTRUIR UNA NUEVA RACIONALIDAD QUE COLOQUE LA VIDA EN EL CENTRO DE LA REFLEXIÓN Y DE LA EXPERIENCIA}

Recuperar las percepciones de ecodependencia e interdependencia como señas de identidad de lo humano y desplazar los ídolos del crecimiento económico y del progreso ligado al crecimiento son tareas tan pendientes como urgentes para conseguir un vuelco en la hegemonía cultural que ha conquistado el capitalismo.

El difícil reto es conseguir que las personas deseen esta transición, quieran esos cambios. No hay atajos y el trabajo colectivo en instituciones, redes y organizaciones ciudadanas de todo tipo es imprescindible. Se trata de una tarea de pedagogía popular a realizar casi puerta a puerta. Para poder cambiar, necesitamos desvelar los mitos y ficciones y componer otro relato cultural más armónico con la consistencia humana.

Resituar a los seres humanos en términos ecológicos y en cuanto a las relaciones de reciprocidad y apoyo mutuo, base de su éxito evolutivo, requiere acometer una importante tarea educativa.

Quien ha crecido en una gran ciudad y vive rodeado de cemento no tiene nada fácil ser consciente de la ecodependencia. Sin embargo la conciencia de ser seres vivos y vulnerables es uno de los primeros pasos para repensar el mundo en clave ecológica.

La alfabetización ecológica es un asunto crucial. Nos referimos aquí a entender, valorar y querer las diferentes formas de vida y reconocernos como partes de una red formada por el tierra, agua, plantas y aire. Es preciso reconocer que el sol es el motor que moviliza toda 
la dinámica natural y que es el origen de toda la energía que utilizamos. Es importante comprender que la fotosíntesis es la tecnología que sostiene la vida; qué en gran medida somos agua y cuál es el papel del agua en la creación de comunidades humanas, en la geopolítica o en la economía; conocer las consecuencias de la producción industrial de alimentos (en la insalubridad de los alimentos; en el empobrecimiento y envenenamiento de los suelos; en el desecamiento de acuíferos; en el coste energético y la dependencia del petróleo; en la dependencia de los agricultores de los suministros de semillas, abonos y pesticidas...) .

Colocar la vida en el centro de la experiencia es también ser consciente del nacimiento, el crecimiento o la muerte; es aprender el respeto a los animales no humanos y reconocernos parecidos y diferentes a estos compañeros de viaje; es desentrañar las relaciones complejas y dinámicas de los ecosistemas que no funcionan como mecanos. Colocar la vida en el centro significa comprender el valor de la cooperación y del apoyo mutuo. La interdependencia es una experiencia práctica esencial para la valoración de la vida y para la reconstrucción de las sociedades. Visibilizar y dar valor al trabajo de cuidados y exigir la reorganización y el reparto equitativo de este trabajo son señas irrenunciables en sociedades que quieran situar el bienestar como objetivo del metabolismo social.

Trabajar la centralidad de la vida tiene por objeto suavizar del fuerte antropocentrismo de nuestra cultura y asomarnos a una democracia de la Tierra (Shiva, 2006) que sea capaz de integrar la condición de ser eco e interdependientes con sociedades justas.

Se trata de "renaturalizar" a los seres humanos, ajustando la organización política, relacional, doméstica y económica a las condiciones de la vida, que vienen dadas por el hecho de formar parte de la comunidad biótica. Una "renaturalización" que es al tiempo "reculturización" (construcción de una nueva cultura) que convierte en visible la ecodependencia e interdependencia para mujeres y hombres (Herrero et al., 2011).

\section{Retos para el movimiento ecologista}

Si partimos de la hipótesis de que, aunque incompletas, disponemos de ciertas propuestas y directrices para comenzar a ensayar transiciones socioecológicas hacia otro modelo de economía y organización social, nos enfrentamos a un problema para el que, sin embargo, nos encontramos en una situación de inmadurez preocupante. Nos encontramos ante una situación de enorme debilidad en la respuesta social. Existe una enorme grieta entre la dureza de la ofensiva neoliberal y la creciente, pero aún embrionaria, movilización social.

Existe a nuestro juicio, un enorme desnivel entre la brutalidad de los ajustes que vivimos y la capacidad para hacerles frente. Hoy nos falta poder político construido desde abajo para forzar las transiciones.

En este camino no existen atajos posibles. Sólo vale la construcción colectiva, la escucha, el debate, la deliberación, la suma y la participación activa. 
Los seres humanos a lo largo de decenas de miles de años han sido capaces de organizar complejos modos de supervivencia y de organización social. La organización colectiva ha creado y crea posibilidades nuevas de intervenir en el mundo y ejercer el poder. Un poder del que muchos grupos humanos han sido expropiados. Un trabajo socialmente necesario hoy es retejer esa malla comunitaria.

Reconstruir la sociedad también requiere alentar la diversidad entre las personas. En un momento en el que es importante sumar mayorías y construir poder colectivo es fundamental interiorizar las ventajas de la diversidad. En un colectivo que busca y valora la heterogeneidad nadie se siente fuera, ni es menos que el resto, cada cual encuentra el lugar donde es capaz de recibir y aportar. Por otro lado, para poder sumar mayorías e intentar convencer es necesario compartir espacios con las personas no convencidas. Con cierta frecuencia, los movimientos sociales rechazan participar en espacios en los que deben convivir con organizaciones o personas que no comparten la necesidad de un cambio de modelo y creen que meras reformas puntuales servirán para salir del paso. No se nos ocurre ninguna forma de conseguir abrir un debate que permita ampliar los entornos de personas ya convencidas que no pase por ocupar nuevos espacios.

Son necesarios los cambios por arriba y por abajo y debemos ser conscientes de las falsas dicotomías que también pueblan el panorama de los movimientos político-sociales. En nuestra opinión la autoorganización no se contrapone con la representación. Los proyectos locales y autogestionados firmemente anclados en los territorios, son vulnerables si no se actúa también en la escalas macro. También es cierto, que las transformaciones en el ámbito institucional, sin "pueblo" que las defienda y presione para conseguirlas son poco probables. En ocasiones, dentro del movimiento ecologista se establecen estas dicotomías y, o se minusvaloran las experiencias alternativas porque no suponen una solución global, o se desprecian los cambios en las instituciones. Nos encontramos en un momento de emergencia en el que, a nuestro juicio todo es necesario.

Los entornos precarios y vulnerables en los que se ha perdido el tejido asociativo y no abundan las redes familiares y sociales son caldo de cultivo para la emergencia de brotes fascistas. La única forma de vacunarse contra el fascismo es la solidaridad. Por ello, en nuestra opinión hay que aprender de movimientos como la Plataforma de Afectados por las Hipotecas, un movimiento de base que sabe conjugar las propuestas y exigencias de cambio en los marcos normativos, la denuncia contundente y el apoyo a las personas con nombre y apellidos durante los desahucios. Es un movimiento que encarna bien lo que es feminismo ha defendido con fuerza: la idea de que lo personal es también político. Es una forma de superar la dualidad de la política de las categorías abstractas y la de la experiencia cotidiana.

El movimiento ecologista en muchas ocasiones tiene dificultad para conectar con las preocupaciones de las personas. En sociedades tan antropocéntricas como las nuestras es importante trabajar para actuar como "estructuras de mediación entre la naturaleza 
y las personas". El concepto de pobreza energética, por ejemplo, permite ligar una preocupación material de las personas, con la crisis energética y, por tanto con la cuestión de los límites. Los fenómenos climáticos extremos pueden ayudar a visibilizar algo complejo de percibir como es la alteración de los mecanismos de regulación del clima. El deterioro de la salud debido a la contaminación del aire puede ayudar a comprender el disparate de la movilidad excesiva. Los papeles de Bárcenas y las presuntas adjudicaciones a cambio de sobres permiten cuestionar algo hasta ahora intocable como era la bondad de las grandes infraestructuras, fueran o no necesarias. Se trata de ayudar a establecer vínculos y relaciones entre la crisis ecológica y lo que nos preocupa en la vida cotidiana. Considerar políticamente las emociones es también importante. El ecologismo social tiene una importante riqueza conceptual y se mueve con soltura en el campo de lo racional pero tiene dificultades para conectar con las emociones. No hay revolución sin pasión, sin amor por la vida y por las personas. Invertir tiempo y energía en una lucha tan desigual, en la que a veces se tiene tantas dudas sobre el resultado que tendrá, sólo es posible si vive con sentido pleno, con la cabeza y con el corazón. Convertir los espacios de activismo en lugares que dan sentido vital y aportan relaciones significativas de confianza es fundamental. Las personas que participamos en espacios de esas características sabemos que no estamos solas y nos hacemos fuertes, dentro de nuestra vulnerabilidad, gracias al afecto, amistad y cariño que recibimos de quienes comparten con nosotras resistencias, construcciones y sueños.

Después de estas reflexiones queda al fin un interrogante esencial: ¿Seremos capaces de forzar estas transiciones?

No tenemos certezas. Sólo dos: la urgencia en el cambio y que tenemos la responsabilidad de intentarlo, cambiar el rumbo suicida de la historia y reinventar un mundo social y ecológicamente sostenible. Ese es el empeño del movimiento ecologista. 


\section{REFERENCIAS BIBLIOGRÁFICAS}

Bosch, A.; Carrasco, C. y Grau, E. (2005) "Verde que te quiero violeta. Encuentros y desencuentros entre feminismo y ecologismo". En Enric Tello (ed.) La historia cuenta. Del crecimiento económico al desarrollo humano sostenible. Barcelona: Ediciones El Viejo Topo, pp. 321-346.

Carpintero, Óscar (2005) El metabolismo de la economía española. Recursos naturales y huella ecológica 1955-2000. Madrid: Colección Economía vs Naturaleza, Fundación César Manrique.

Carpintero, Óscar y Bellver, José (2013) "Es posible la sostenibilidad ambiental de la economía española”. En Worldwatch Institute (ed.) La situación del Mundo 2013. ¿Es aún posible lograr la sostenibilidad? Barcelona: Icaria y Fuhem Ecosocial, pp. 557-579, 651656.

Carrasco, Cristina (2009) "Tiempos y trabajo desde la experiencia femenina". Papeles de Relaciones Ecosociales y Cambio Global, 108.

Commoner, Barry (1976) The Poverty of Power: Energy and the Economic Crisis. New York: Random House.

Commoner, Barry (1971) The Closing Circle: Nature, Man, and Technology. New York: Knopf.

Federeci, Silvia (2010) Calibán y la bruja. Mujeres, cuerpo y acumulación originaria. Madrid: Traficantes de Sueños.

Fernández Durán, Ramón (2008). La historia trágica del petróleo. Madrid: Virus y Libros en Acción.

Fernández Durán, Ramón (2010) El Antropoceno: la crisis ecológica se hace mundial. La expansión del capitalismo global choca con la Biosfera. Madrid: Virus y Libros en Acción. García, Ernest (2006) “El Cambio más allá de los límites al crecimiento: un nuevo referente para el realismo en la sociología ecológica”. En Luis Enrique Espinoza y Valentín Cabero (eds.) Sociedad y Medio Ambiente. Salamanca: Ediciones Universidad Salamanca, pp. $52-$ 74 .

Hernando, Ana (2012) La fantasía de la individualidad. Madrid: Katz Editores

Herrero, Yayo (2012) "Propuestas ecofeministas para un sistema cargado de deudas". Revista de Economía Crítica, 13, pp. 30-54.

Herrero, Yayo (2013) "Miradas ecofeministas para transitar a un mundo justo y sostenible". Revista de Economía Crítica, 16, pp. 40-65.

Herrero, Y.; Cembranos, F. y Pascual, M. (coords.) (2011) Cambiar las gafas para mirar el mundo. Hacia una cultura de las sostenibilidad. Madrid: Libros en Acción.

Martínez Alier, Joan (2004) El ecologismo de los pobres: conflictos ambientales y lenguajes de valoración. Barcelona: Icaria 
Meadows, Donella H. (1972) Los límites al crecimiento: informe al Club de Roma sobre el predicamento de la humanidad. México D.F.: Fondo de Cultura Económica.

Meadows, D.H., Randers, J. y Meadows, D.L. (2004) Limits to growth: the 30 years update. White River Junction,VT: Chelsea Green.

Naredo, José Manuel. (2006) Raíces económicas del deterioro ecológico y social. Más allá de los dogmas. Madrid: Siglo XXI.

Odum, Howard Thomas (1971) Environment, Power and Society. New York: John Wiley and sons.

Odum, Howard Thomas y Odum, Elisabeth (1976) Energy basis for Man and Nature. New York: McGraw-Hill Rook Company.

Pérez Orozco, Amaia (2006a) "Amenaza tormenta: la crisis de los cuidados y la reorganización del sistema económico". Revista de Economía Crítica, 5, pp.7-37.

Pérez Orozco Amaia (2006b). Perspectivas feministas en torno a la economía: el caso de los cuidados. Madrid: Consejo Económico y Social.

Piccio, Antonella (1992) Social Reproduction: the political economy of Labour Market. Cambridge: Cambridge University Press.

Precarias a la Deriva (2004) A la deriva por los circuitos de la precariedad femenina. Madrid: Traficantes de Sueños.

Reid, W. et al. (dir.) (2005) Informe evaluación ecosistemas del milenio. www. milleniumassessment.org [Consultado el 17 de julio de 2010].

Riechmann, Jorge (2005) Biomímesis. Ensayos sobre imitación de la naturaleza, ecosocialismo y autocontención. Madrid: La Catarata.

Riechmann Jorge (2009) La habitación de Pascal. Madrid: Ediciones La Catarata.

Rockström, J. et al. (2009) "Planetary boundaries: exploring de safe operating space for Humanity”. Ecology and Society, 14 (2), pp.32.

Schumacher, Ernst F. (1973) Small is Beautiful: economics as if people mattered. London: Blond and Brigs.

Worldwatch Institute (2013) La situación del Mundo 2013. ¿Es aún posible lograr la sostenibilidad? Barcelona: Icaria y Fuhem Ecosocial. 